\title{
TED TALK IN THE ESP CLASSROOM OF PHILOSOPHY STUDENTS
}

\author{
Svetlana Danilina \\ Taras Shevchenko National University of Kyiv, Ukraine \\ sv.danilina@gmail.com \\ Viktoriia Shabunina \\ Taras Shevchenko National University of Kyiv, Ukraine \\ vshabunina@gmail.com
}

\begin{abstract}
Using authentic materials in teaching ESP is part and parcel of communicative approach methodology. Unadapted materials bring the classroom closer to real-life language use and overall make language learning more meaningful and engaging for students. The needs analysis of Ukrainian students, which shows that many of them wish to continue their studies in English language universities abroad, makes the use of authentic materials particularly relevant, as they model the situations that students can potentially face in their future professional life. The presence of a vast array of authentic materials available today is both a challenge and a benefit for teachers, since they have to choose the ones which would meet their students' needs and expectations. Based on an ESP class taught to philosophy students, this article offers a suggestion on how to approach teaching presentation making skills and provides the practical outcome of using a TEDx talk in the ESP classroom. The featured talk, which focuses on today's perception of stoicism, was followed by some tasks to promote students' critical thinking and facilitate their future presentation planning, as well as by the students' own presentations in which they had to make use of the strategies discussed in class. Listening to the genuine presentation and using it as a model for presentations of their own follows the principles of CLIL (Content and Language Integrated Learning), which can benefit students by its explicit emphasis on the content and gives them a chance to acquire syntax, lexis, and discourse style skills as a by-product of content-oriented learning.
\end{abstract}

Keywords: higher education; presentation making skills; TED talk; ESP; CLIL; communicative methodology; authentic materials.

\section{Introduction}

The use of authentic language materials in teaching a foreign language has been gaining popularity since the advent of communicative approach in the 1980s, when texts, artificially tailored for classroom purposes, were condemned as too unnatural, providing "poor models of real language use, and obsessively concerned with the forms of the language, particularly its grammar patterns, at the expense of more communicative features of the text" (Thornbury, 2005, p. 104). As practical experience proves, university students whose level of English is beyond intermediate, react much more enthusiastically to the use of authentic texts in the classroom (even more so to the ones related to their university specialism) than to working with adapted texts, which they can find boring and demotivating. The central issue of applying authentic materials in teaching ESP to philosophy students seems to coincide with Thornbury's remark on the specificity of using this sort of material in general, i.e. "how to ensure that learners understood such texts, and how to decide which language features of these texts should be selected for teaching purposes" (Thornbury, 2005, p. 106), as authentic philosophy materials demand both a high level of the English language command (making them practically inapplicable for lower level students), as well as a certain level of subject matter knowledge.

\section{The analysis of recent studies and publications}

Problems of using authentic materials in teaching English to university students of philosophy have been in the centre of attention of Prof. Savka Blagojević (2013), who maintains that "an authentic language sample can be successfully selected out of a variety of the 'real life' materials, which communicate messages of different kinds, content, length, and have different aims and purposes, and then they can be used for pedagogical purposes, i.e. for foreign language teaching" (p. 115). However, there is a contradiction in the way of referring to authentic language materials, since the latter can be viewed as "texts produced by native speakers for a non-pedagogical purpose" (Bacon \& Finneman, 1990, p. 459), or "as the material which has not been especially designed for language teaching, but produced for purposes other than to teach language" (Nunan, 1988, p. 99), or texts "produced without L2 learners in mind" (Nguyen \& Boers, 2018, p. 18). For a summary of various definitions of authentic materials see the article by Azri \& Al Rashdi (2014).

The above considerations apply to the ICT (and, particularly, TED Talk platform) use in language teaching. Although some may doubt the authenticity of TED materials from the perspective of their nonmandatory 'nativeness' or their increasing usage as official coursebook basis, these talks can be viewed as authentic in the way they concentrate on their content, not on a particular language feature needed to be a highlight of some linguistic analysis, and although a talk may be produced by a non-native speaker of 
English, it does reflect a real language use, and it is not purposefully simplified nor organised in a particular way to suit certain grammar or lexical exercises. To avoid misinterpretations then, this paper will refer to the TED Talk material as to a 'genuine' rather than 'authentic' material, the former, in Savka Blagojević's terms, signifying that they are "the original texts which could be successfully used in a language classroom as authentic teaching material, provided they communicate with their recipients in an authentic way, and are used for a real-life communicative purpose" (Blagojević, 2013, p. 116).

Wegener (2008) points out three functions that authentic texts serve in the ESP classroom: "First, inviting authentic materials from the learners' work environment to the classroom (...) Second, the ESP teacher always looks for texts that are as close to the learners' target situations in their jobs as possible (...) Third, authentic texts serve as sources of information for the teacher and may already be collected during the needs analysis period" (p. 137). From this point of view, the selection of an original presentation is relevant for a university ESP lesson because presentation making skill is traditionally among top priorities on students needs list, whose importance, along with academic writing skills, can hardly be overestimated for future scholars aiming at participating in international conferences, giving public speeches, and delivering university lectures. An argument against the use of genuine texts could be their complexity which does not correspond to the learner's current level of linguistic competence and thus can demotivate them. Therefore, another feature of ESP texts, as specified by Gilmore (2007), is that: as authentic texts reflect the real-life language, they contain a great diversity of grammatical and lexical elements, which means that they are much more abundant in language forms than the texts constructed for language teaching purposes. Quoting Blagojević (2013), "from a language teacher's point of view, such an abundance in linguistic devices may be considered a disadvantage. The language elements are less frequently repeated in this language sample than in the texts designed for language teaching courses, in which the elements planned to be taught are repeated several times in order to be easily recognised by language learners" (p. 118).

As for the research which pertains specifically to the use of TED talks in the EFL classroom, Wingrove (2018) observes that "TED talks were found to have lower AVL [Academic Vocabulary List] representation than the university lectures" and "the notion that TED talks are suitably equivalent to academic discourse to be considered academic listening materials is a widely shared assumption which has yet to face any real scrutiny" (p. 79), while Nurmukhamedov (2017) maintains that: "The lecture content of TED Talks does not generally use language that contains precise scientific terminology" (p. 780). On the other hand, according to Nurmuhamedov's (2017) research, "despite the usefulness of TED Talks presentations for learning presentation techniques, improving listening skills, and keeping oneself updated about innovations occurring in the world, TED Talks presentations cannot be entirely comprehended if learners do not have a sufficient vocabulary in English" (p.770), Given the above, another argument for selecting the presentation in question was that it was delivered by a non-native speaker of English, a professor of philosophy from Lithuania. This fact ensured that the material would not turn out too complicated for students from the linguistic point of view, while the concept of stoicism, by now well familiar to them, would foster both their interest in listening to the content of the presentation and their concentration on the analysis of its structure.

It is worth emphasising that the activity of listening to the genuine presentation intended for generating the students' interest in both its content and the way it is organised follows the principles of CLIL (Content and Language Integrated Learning). Combining ESP and CLIL approach can benefit students by giving them different perspectives on language learning. As Rubenstein (2012) states in respect to using TED talks in foreign language instruction, "In-class time can (...) be spent exploring the content, asking questions, applying the material to real situations, or developing methods to extend the content" (p. 262). CLIL explicitly places a greater emphasis on the content than ESP, because in the former case teachers have joint content and language expertise that ESP practitioners commonly lack (Torregrosa Benavent \& Peñamaría, 2011). S. Krashen (2009) points out that while the ESP requires a detailed analysis of syntax, vocabulary, and discourse of a subfield, CLIL "focuses only on the topic, the information or skill to be learned, the assumption being that much of the syntax, vocabulary, and discourse style will be acquired along with the subject matter" (p. 170).

Thus, the objective of this paper is to prove the hypothesis that in their ESP classroom, university students can benefit from a CLIL component of language learning, while CLIL activities can be based on genuine ICT materials (in this case, a TEDx presentation). CLIL component, with its focus on relevant content and skills, can effectively complement traditional ESP approach, which focuses mainly on linguistic form and meaning, thus meeting university students' needs and expectations more closely. 


\section{Method}

The article makes use of the case study approach in discussing an application of ICT in ESP classroom and in the interpretation of research results.

\section{Case description}

The series of presentation making skills classes was part of ESP course taught to 12 fourth-year philosophy students, whose CEFR level is B2-C1, in March-April 2017 at the Faculty of Philosophy of the Taras Shevchenko National University of Kyiv. The group is representative of the general body of the fourth year students of the philosophy faculty, whose CEFR level is B2-C1 in most cases. All of the students in the group had made presentations in English at school and/ or university classroom, while four of them had spoken publicly in English at the annual philosophy conference held at the Taras Shevchenko University. The students named the improvement of their presentation making skills among their priorities on their needs analysis survey conducted at the beginning of the academic year.

In the first class, as a lead-in stage of the activity, the students were asked to work in groups of three and brainstorm the three things that make a good presentation. This was done to introduce the topic of the lesson to the students, to activate their schemata, and to prepare them for further receptive and productive stages of the lesson. After a short discussion, the students were offered to present their ideas on board.

To build on the ideas they had put forward and expand on the components of successful vs nonsuccessful presentations, the students were asked to work in pairs and split some public speech features into DO and DON'T columns (establish eye-contact with the audience; answer all questions immediately; apologise for the mistakes you make; stand in one place; restrain your gestures; include all details of your speech into visual aids; select one person in the audience and address him/her; ask your audience questions; use different intonation patterns and pace of speech; make jokes). Pairs then discussed their findings with other pairs and then a whole group feedback followed to compare and comment on the students' ideas.

The next stage was listening to the talk presented by Algirdas Davidavicius of Vytautas Magnus University (Lithuania) at TEDx platform on the re-emergence of the principles of ancient Stoics in our technological age (https://www.youtube.com/watch?v=xLoWRmwrSPk). The speaker's pace, the range of vocabulary and easy-to-follow pronunciation were not likely to pose any comprehension issues for listeners at upper-intermediate to advanced levels of proficiency. The term that had to be revised with (introduced to) the students at the pre-listening stage though was resilience as this was the key concept in the conclusion that the speaker came to.

The listening stage was split into two parts: 1)listening for detail and 2)analysis of the techniques employed by the speaker.

Pre-listening for detail: Before listening to the presentation, the students were asked to brainstorm in groups of three the ideas of ancient stoics that they would believe could be relevant nowadays. Keeping in mind their findings, the students were asked to compare their assumptions with the ideas presented by the speaker. Such activity was meant to create a certain information gap that the students might find challenging to complete and thus the listening task would be more meaningful and cognitively engaging for the students. Because the content of the presentation was quite comprehensible, it was possible to offer the students not just to listen to the presentation for gist but ask them to listen for detail and compare the speaker's ideas with their own.

After the students listened to the presentation for the first time, they were put in groups of three to compare their initial ideas with those of the speaker, followed by the whole group feedback. The students were also asked about their general impression of the talk, whether they found it engaging, boring, too lengthy, etc. Generally, the students agreed they had been intrigued by the name of the lecture but then thought that the introduction had turned out too long, and the very essence of the presentation seemed to have been crumpled hastily in the last 2 minutes of the talk.

Completing the first listening stage made it possible for the students to consciously concentrate on the analysis of presentation making skills and not be distracted by the issues of content in the second stage.

Thus, in the second pre-listening stage, the students were asked to listen to the presentation for the second time and take notes on the following:

1) STRUCTURE of the talk - what they like about the structure of the presentation? Any tips they would like to remember regarding the introduction, main body, conclusion? How does the lecturer put the audience into the right mindset? Are the introduction, main body and conclusion well balanced?

2) STYLE / COHESION: any stylistic devices they would retain for future use (repetition, rhetorical questions, parallel constructions, metaphors, etc)?

3) DELIVERY: any interesting observations as for delivery, i.e. the behaviour of the speaker, his body 
language, the pitch of his voice, emotionality, whether he is reading his text out/ improvising, etc?

4) The use of VISUAL AIDS: was he using them a lot? Were his slides colourful, engaging, informative, packed with text?

The talk lasted for 16 minutes with most of the students taking notes, others just listening to the presenter. After the talk had finished, the students were put into pairs to discuss their findings. Students commented as follows:

STRUCTURE: the introduction was too long; the main part too short; he sounded like he wanted to say something else but was short of time; to put the audience in the right mindset and establish rapport with the listeners, the speaker referred to well known brands (Nike and its slogan), philosophers \& concepts (Francis Fukuyama and the end of history), referred to his own experience in the time period well known to audience;

STYLE: noticed repetitions of the key concepts ('ancient stoicism', 'social circles'), comparisons (like a magic bullet), rhetorical questions (but why?); parallel constructions: ... as a discipline of philosophy, as a school of thought, as a practical philosophy; ... to the frustrations, to the distress, to the life crises that ancient people had...; ... to learn this, to learn that, to get everywhere on time, to get more productive;

DELIVERY: well paced; no tension; emotional; not reading from notes; sarcastic intonation at times: magic bullet that will empower you to achieve everything in life;

VISUAL AIDS: succinct slides just with key concept/ key question displayed.

After the whole group feedback, we proceeded with the whole group discussion to build on the identified features and expand them further to make a summary. The Ss were asked to make notes:

1) Features of STRUCTURE were summarised which can make a presentation more engaging, establishing rapport with the audience (starting with famous quotation, creating suspense - to a certain extent, this was done in this talk as well, as the speaker did not nominate the key concept until the end of his introduction, he was accumulating information to lead to the nomination of the topic), interesting stories, anecdotes, to get the audience going; weaving concrete data or scientific reference into your text to promote trustworthiness of the information;

2) STYLE: The importance of chunking, parallel constructions and repetition of keywords to facilitate reception, rhetorical questions to keep the listeners' attention, interspersing the generally semi-formal style of presentation with humour/ informal remarks to liven it up, facilitate reception: here, the speaker used informal vocabulary, referred to himself ironically: 'Guru of some ancient bookish bullshit', talked with humour about ancient stoics: 'Dressed in funny clothes, bearded like me'. 'Having time and leisure not to do anything'; referred to his emotions: I was annoyed/ surprised;

3) DELIVERY: the right pace, varying intonation patterns, changing the pitch of voice to signal sarcasm, questions, assuming interlocutor's role while speaking:

4) VISUAL AIDS: need to be succinct and easily comprehensible (big enough script, only key concepts, pictures/ graphs where appropriate).

The discussion continued with drawing the students' attention to the moments when the speaker made the audience laugh. And asking the students what could have been done better (the answer was to reduce the introduction and dwell more on his vision of modern stoicism).

Last but not least, although the linguistic component itself was not the main focus of our attention, it was emphasised how important it is for philosophy students to double-check the pronunciation of proper names of philosophers and/ or heroes of myths they refer to in their presentations.

As hometask, the students were asked to watch and reflect on Simon Sinek's (one of the most popular TED Talks) presentation and prepare a 10 to 15 -minute presentation on a philosophy subject that interests them applying the techniques discussed in the lesson.

\section{Results}

The outcome of the presentation techniques analysis lesson was 11 presentations made by the group in the course of the next four classes. Each presentation was followed by questions (if available) from the students, the whole-group discussion of the issue covered, and by the feedback on the strong points that the students could identify and on the points which could have been done differently:

1) The first student to give her presentation was more interested in political science than philosophy, thus she made a presentation on Donald Trump and some theories related to his allegedly fabricated elections. The presentation was done with the help of numerous photos of Trump and his wife that the speaker had downloaded from the internet, as well as a couple of short videos of Mr Trump's inauguration. The presenter failed to give any substantial comment on her materials or maintain contact with her audience. Her presentation failed to generate high interest in the audience.

2) Another presentation which was made with extensive use of ICT was that on philosophy of gender 
and how it informs the role of women in Ukrainian society. The presentation contained about 20 slides, with the speaker trying to comment on them by reading from a printout. Because she aimed at reducing the time of her presentation, she would be increasing the speed of her reading making her text quite hard for the audience to understand. As a result, most students were not attending to her presentation watching their smartphone screens instead, while the student had to be interrupted after her presentation had lasted for twenty minutes. A couple of questions followed. In the follow-up discussion it was emphasised that the topic had turned out too extensive, and the Ss had to think carefully of the aspect they would like to cover in their presentation and on making their speech comprehensible to the audience of non-native English speakers.

3) on Freire's views on liberating education - the student focused on the four main 'concerns' of Freire's in the field of de-hierarchisation of education. Her presentation centred round the four slides with the key concepts of his theory which she commented on using her notes. She maintained the eye contact with the audience, was relaxed, drew parallels between Freire's ideas and possible changes to the Ukrainian educational system. Although the concepts covered were rather difficult to understand for a person not specialising in philosophy (e.g., the English teacher), the presentation resulted in a number of questions relating to the future of Ukrainian education, its possible liberalisation, prospects of school and university curricula gaining more flexibility, etc. Overall, the students seemed more interested in the practical aspect of applying Freire's theory in Ukrainian reality.

4) on robot ethics - the speaker made a short introduction on first laws of roboethics by Asimov, spoke on recent British Standards Institute article on roboethics and the views of prominent futurists, IT experts, brain explorers, on whether ethical laws can be applied to robots. The presentation started off with a question of the possibility of ethics being applied to non-humans. The speaker continued to pose rhetorical questions to the audience in the course of the whole presentation, the final stage was a practical example of ethical laws which need to be developed for driverless cars and their possible accidents. The speaker felt relaxed, made jokes, kept eye-contact with the audience, he occasionally put some key dates and names on the board, otherwise there were no other visuals involved. At the end he asked the audience to answer the initial question he had asked. The presentation generated a discussion on the need of roboethics, and on the possibility of robots and artificial intelligence getting out of human control.

5) on CETI (Communication with Extraterrestrial Intelligence) - started with a quote from 'Solaris' to create suspense, asked rhetorical questions, maintained eye-contact with the audience, turned to her printedout plan shortly to remind herself of the sequence of the presentation, 6 short slides each featuring one aspect underlying human intra-specific communication, and one slide featuring a sum-up table which contains difference between features of intra-human communication and human-Solaris communication. The presentation was within the time limit and generated an engaging discussion about the prospects of communication with extraterrestrial intelligence.

6) on Gettier problem - the presentation had a clear structure, with a short introduction of what is believed to be three components of knowledge, and how Gettier challenged what is referred to as Justified True Belief. The slides which had pictures and questions on them all related to the dilemma of sheep in the field. The presentation was built interactively with the presenter asking the audience questions, eliciting the ideas of Plato and Russell on the nature of knowledge at the initial stage, and going interactively through the 'sheep case' asking the students if in this case mistaking a poodle for a sheep could be called knowledge. Although challenging for a non-philosopher, the group appeared familiar with the concept and a discussion on the nature of knowledge followed.

7) on the Extended Mind Thesis - the speaker based his presentation on the insightful article by Jerry Fodor, whose style contributed to the liveliness and interactivity of the speech. The speaker managed to condense the content into a ten-minute talk, mostly talking from memory, occasionally looking into a highlighted print-out of the article. There were no slides prepared. The speaker asked rhetorical questions, used metaphors, maintained eye contact with the audience. The students had a discussion on how far can reach the philosophical concept of human mind.

8) on Simmel's philosophy of money - the talk lasted less than 10 minutes. There were no slides prepared. After an introduction on Simmel and his antipositivism, the speaker concentrated on several theses of Simmel's philosophy and mostly read out from his print out. There was not much interaction with the audience, the sentences produced were often too long and complicated to understand. A couple of questions followed but no whole group discussion was generated.

9) on Levi Strauss's interpretation of the Canadian myth of skate dominating the South Wind. After a brief introduction on C.Levi Strauss and his 'Myth and Meaning' the student went on to the philosopher's interpretation of the myth. She had a few slides with the key features of the contents of the myth and essential theses of its scientific interpretation as seen by LS. Although she at times read out her comments to 
the myth, generally the talk was easy to understand. There were no rhetorical questions asked and no suspense creating devices used. The presentation however was clearly structured and easy to follow. It generated a discussion with reference to Losev's and Propp's investigation into the theory of myth and interpretation of Ukrainian/ Russian fairy-tales.

10) on Heidegger's view of thinking - the presentation looked like a short lecture on the concept, with the student mostly reading and occasionally interpreting and expanding on the ideas from her text. The text had been written in English by the student herself therefore was easy to understand from the point of view of grammar constructions, although fairly demanding from the point of view of philosophical concepts she talked about. A couple of questions followed (from students interested in phenomenology), however, not much discussion was called for.

11) On translating Berkeley's "The Theory of Vision or Visual Language" into Ukrainian. After a brief introduction about the philosopher and his main beliefs, the students displayed a number of phrases which were problematic from the point of view of translation. They explained that Berkeley's text had never been translated into Ukrainian, while its Russian translation was no longer relevant as it had been made in Soviet times following the principles of censorship which no longer held. The slides displayed the English phrase, its Russian translation (when available) and Ukrainian translation (often in two options done by the students separately), the presentation was highly interactive as almost the whole group was eager to discuss the translations, supply their own modifications, and comment on the reasons behind them. Most probably, the reason for that was that all the students were familiar with the philosopher and the text, and moreover, at that time they all were attending a workshop in textology where they enjoyed making comparative analysis of original texts written by ancient philosophers and their translations into English and Russian. The presentation exceeded the 15-minute time limit.

The main features of the above presentations and the learners' corresponding CEFR levels are summarised in Table 1 below.

Key Features of the Presentations and Learners' CEFR Levels

Table 1

\begin{tabular}{|l|c|c|c|c|c|c|c|c|c|c|c|}
\hline \multicolumn{1}{|c|}{ KEY FEATURES } & $\mathbf{1}$ & $\mathbf{2}$ & $\mathbf{3}$ & $\mathbf{4}$ & $\mathbf{5}$ & $\mathbf{6}$ & $\mathbf{7}$ & $\mathbf{8}$ & $\mathbf{9}$ & $\mathbf{1 0}$ & $\mathbf{1 1}$ \\
\hline Clear structure & - & + & + & + & + & + & + & + & + & + & + \\
\hline $\begin{array}{l}\text { Stylistic devices used } \\
\text { (rhetorical questions) }\end{array}$ & - & + & - & + & + & + & + & - & - & - & - \\
\hline $\begin{array}{l}\text { Paralinguistic features } \\
\text { (gestures, relaxed posture, } \\
\text { various intonation patterns, } \\
\text { etc) }\end{array}$ & - & - & + & + & + & + & + & - & + & + & + \\
\hline Read from a ready text & - & + & - & - & - & - & - & + & - & + & - \\
\hline Read from notes & - & - & + & + & + & + & + & - & + & - & + \\
\hline Eye-contact with audience & - & - & + & + & + & + & + & - & + & + & + \\
\hline Response from audience & - & - & + & + & + & + & + & - & + & - & + \\
\hline Slides & + & + & + & - & + & + & - & - & + & - & + \\
\hline CEFR level & $\mathbf{B 2 . 1}$ & $\mathbf{C 1}$ & $\mathbf{B 2 . 2}$ & $\mathbf{C 1}$ & $\mathbf{C 1}$ & $\mathbf{C 1}$ & $\mathbf{B 2 . 2}$ & $\mathbf{B 2 2 . 1}$ & $\mathbf{B 2 . 2}$ & $\mathbf{B 2 . 1}$ & $\mathbf{C 1 + B 2 . 1}$ \\
\hline
\end{tabular}

\section{Discussion}

The findings of the present case study prove the idea that learners of English who have reached CEFR levels of B2-C1 can use genuine English language materials to enhance their linguistic and paralinguistic skills. In the context of the speech in question, the students' familiarity with the concept of stoicism also contributed to the ease of its comprehension and made it possible for them to focus on the presentation making skills under discussion rather than concentrate on linguistic devices per se. TED talks come as a an example of expert speakers talking directly to a wide audience of non-experts, which requires the former "to be able to analyse their audience to understand their knowledge, background and interests, and adapt content to them" (di Carlo, 2018, p. 123). This factor could provide a valuable model for students in terms of assessing their target audience while planning their presentations, as the issue of selecting an appropriate presentation topic is particularly relevant for philosophy students. Because their subject matter is so complex and can easily get incomprehensible for the listeners, they need to carefully think of the terms they are going to use, of chunking, and the complexity of grammar (especially when addressing non-native speakers), of how deep they can go into the subject depending on the time constraints and the level of their audience's familiarity with the concept. 
Wingrove (2017) states that the driving force behind TED's successful speeches is "the ability to wow, inspire, and amaze an audience" (p. 80), while di Carlo (2018) observes that to be successful "presentations should be dynamic and try to transmit enthusiasm, passion, and sense of belongingness" (p. 122). As was seen from the students' presentations, in most cases $(7$ out of $11,63 \%$ ) conveying the sense of belongingness, or the sense of inclusivity, was linked to non-reading from the prepared text and maintaining eye contact with the audience. These presentations achieved their communicative goals (gained audience response and engagement) and therefore can be considered successful. As for the four presentations which did not yield response from the audience, all of them were read from the ready text and in three of them the speaker failed to maintain eye contact with the audience.

Summarising other features, 10 presentations (90\%) out of 11 had a clear logical structure; 5 (45\%) made use of some stylistic devices, mostly, rhetoric questions, with the means of creating suspense, using famous quotes or telling anecdotes almost never used. The reason for it might be the 'serious', academic subject matter of their presentations, as well as awareness of speaking in front of familiar, and at the same time, professional audience of their groupmates, which could have demotivated them from being utterly 'artistic' in their presentations; 8 (72\%) featured delivery aspects which had been analysed out of which the most frequently used were relaxed body language and natural gesturing. 7 (63\%) out of 11 presentations managed to yield response from the audience and generated interest to further discuss their topics, this was largely a result of the students' trying to avoid reading whole texts from printouts / tablets, which led to them sounding natural and maintaining rapport with the audience.

It should also be noted that most students seem to believe that the style of presentation has to be quite formal (this could be the result of mostly lectures they are exposed to at the university), they need to overcome this stereotype by listening to a multitude of speeches (TED Talk provides a vast array of those) and analyse the register of English-language presentations.

\section{Conclusions}

It can be concluded that an ESP lesson which focused primarily on presentation making techniques rather than on its linguistic content/ form turned out fairly useful for philosophy students at B2-C1 level.

They had a chance to try making English language presentation in the safe environment of the classroom, which obviously reduced their anxiety and promoted their concentration on the techniques under discussion. While the students predictably did not have many problems related to language use per se when making presentations (they did make errors but those did not inhibit understanding) and were quite clear on structuring their presentations logically, their main difficulty seemed to lie in organisational and paralinguistic skills: choosing the appropriate concept to present to meet the time-limit, keeping to the right register of the discourse, interacting with the audience, in other words, achieving the pragmatic aims of their linguistic act. As presentation making was progressing from one class to the next, it could be observed that the speakers were becoming more relaxed about their speaking and less dependent on their prepared printouts, unlike the first presentations they mostly managed to keep within 10-15 minute time limit, maintained rapport with their audience, avoided including excessive detail onto their slides, managed to generate interest in their audience and answered their questions.

An engaging presentation is made by a combination of interesting material which is thoughtfully presented verbally and through visual aids, as well as appropriate paralinguistic features. It was predictable then that, overall, the students who were less proficient in their language skills made less impressive presentations. Out of the 12 students in the group 4 have a B2.1 level of proficiency, whereas the rest are between high B2-C1 level. The presentations which failed to generate much interest in the audience were mostly done by the 'weaker' students, although the second, longest, presentation was done by one of the strongest students who has a tendency of 'overdoing' things.

Thus, with a prominent emphasis given to the linguistic and stylistic component of presentation making (chunking, parallel constructions, rhetoric questions, creating suspense, telling anecdotes), the students will have a chance to consciously focus on these aspects, and will become aware of the importance of including the features into their public speaking. A perspective of further research could be investigating into the ways of raising the effectiveness of teaching presentation making skills, in particular of the linguistic resources responsible for conveying the sense of belongingness - "stance, pathos, humour, lexical patterns, etc" (di Carlo, 2018, p. 123), and thus responsible for the success of the presentation. 


\section{References:}

Al Azri, R. H. \& Al Rashdi, M. H. (2014). The Effect of Using Authentic Materials in Teaching. International Journal of Scientific and Technology Research, 3 (10), 249-254. Retrieved April, 12, 2018 from https://pdfs.semanticscholar.org/a8da/ed79131bf72bd4e51d1e21212426e73113b7.pdf

Bacon, S. \& Finneman, M. (1990). A study of attitudes, motives, and strategies of university foreign language students and their disposition to authentic oral and written input. Modern Language Journal, 74 (4), $459-473$. http://dx.doi.org/10.2307/328520

Blagojević, S. (2013). Original Texts as Authentic ESP Teaching Material - the Case of Philosophy. ESP Today, 1 (1), 113-126, 2013. Retrieved April, 12, 2018, from https://www.esptodayjournal.org/pdf/vol_1_1/7.\%20SAVKA\%20BLAGOJEVIC$\% 20$ full\%20text.pdf

di Carlo, G. S. (2018). Patterns of Clusivity in TED Talks: When 'you' and 'I' become 'we'. Iberica, 35, 119-144. Retrieved May, 23, 2018, from http://www.aelfe.org/documents/35_05_IBERICA.pdf

Gilmore, A. (2007). Authentic materials and authenticity in foreign language learning. Language Teaching, 40(2), 97-118. http://dx.doi.org/10.1017/S0261444807004144

Krashen, S. (2009). Principles and Practice in Second Language Acquisition ( $1^{\text {st }}$ Internet Edition).

Nguyen, C. D. \& Boers, F. (2018). The Effect of Content Retelling on Vocabulary Uptake from a TED Talk. TESOL Quarterly, 52 (1), 1-25. https://doi.org/10.1002/tesq.441

Nunan, D. (1988). The Learner-Centered Curriculum. Cambridge: Cambridge University Press. https://doi.org/10.1017/cbo9781139524506

Nurmukhamedov, U. (2017). Lexical Coverage of TED Talks: Implications for Vocabulary Instruction. TESOL Journal, 8(4), 768790. http://dx.doi.org/10.1002/tesj.323

Rubenstein, L.D. (2012). Using TED Talks to Inspire Thoughtful Practice. The Teacher Educator, 47(4), $261-267$. https://doi.org/10.1080/08878730.2012.713303

Thornbury, S. (2005). Beyond the Sentence. Introduction to Discourse Analysis (1st ed). Macmillan Publishers Limited.

Torregrosa Benavent, G. \& Sánchez-Reyes Peñamaría, S. (2011). Use of authentic materials in the ESP classroom. Encuentro, 20, 89-94. Retrieved April, 12, 2018 from https://files.eric.ed.gov/fulltext/ED530013.pdf

Wegener, B. (2008). Corporate English language training: The way to customized materials. In J. Schmied, \& C.Haase (Eds.), English projects in teaching and research in Central Europe (pp. 127-146). Göttingen: Cuvillier Verlag.

Wingrove, P. (2017). How suitable are TED talks for academic listening? Journal of English for Academic Purposes, 30, 79-95. http://dx.doi.org/10.1016/j.jeap.2017.10.010 